\title{
Drug repositioning for treatment-resistant depression: insights from a pharmacogenomic study
}

Chiara Fabbri ${ }^{1,10}$, Siegfried Kasper ${ }^{2}$, Joseph Zohar ${ }^{3}$, Daniel Souery ${ }^{4}$, Stuart Montgomery ${ }^{5}$, Diego Albani ${ }^{6}$, Gianluigi Forloni ${ }^{6}$, Panagiotis Ferentinos ${ }^{7}$, Dan Rujescu ${ }^{8}$, Julien Mendlewicz ${ }^{9}$, Cathryn M. Lewis ${ }^{1}$, Alessandro Serretti ${ }^{10}$

1: Social, Genetic and Developmental Psychiatry Centre, Institute of Psychiatry, Psychology and Neuroscience, King's College London, United Kingdom

2: Department of Psychiatry and Psychotherapy, Medical University Vienna, Austria

3: Department of Psychiatry, Sheba Medical Center, Tel Hashomer, and Sackler School of Medicine, Tel Aviv University, Israel

4: Laboratoire de Psychologie Medicale, Universitè Libre de Bruxelles and Psy Pluriel, Centre Européen de Psychologie Medicale, Brussels

5: Imperial College School of Medicine, London, UK

6: Laboratory of Biology of Neurodegenerative Disorders, Neuroscience Department, Istituto di Ricerche Farmacologiche Mario Negri IRCCS, Milan, Italy

7: Department of Psychiatry, Athens University Medical School, Athens, Greece

8: University Clinic for Psychiatry, Psychotherapy and Psychosomatic, Martin-Luther-University Halle-Wittenberg, Germany

9: Universite' Libre de Bruxelles

10. Department of Biomedical and NeuroMotor Sciences, University of Bologna, Italy

Short title: drug repositioning in treatment-resistant depression

\section{Corresponding author:}

Chiara Fabbri MD PhD

Social, Genetic and Developmental Psychiatry Centre

Institute of Psychiatry, Psychology and Neuroscience

King's College London

De Crespigny Park, Denmark Hill, London, United Kingdom, SE5 8AF chiara.fabbri@kcl.ac.uk chiara.fabbri@yahoo.it 


\begin{abstract}
About 20-30\% of patients with major depressive disorder (MDD) develop treatment-resistant depression (TRD) and finding new effective treatments in these patients has been a challenge. This study aimed to identify new possible pharmacological options for TRD by comparing genes previously associated with this phenotype and known drug targets.

Genes associated with TRD were compared with those coding for targets of drugs in any phase of development, nutraceuticals, proteins and peptides from Drug repurposing Hub, Drug-Gene Interaction database and DrugBank database. We tested if known gene targets were enriched in TRDassociated genes by using a hypergeometric test. Compounds showing a significant enrichment in TRD-associated genes after false-discovery rate (FDR) correction were annotated and compared with those showing enrichment in genes associated with MDD in the last Psychiatric Genomics Consortium genome-wide association study.

Among a total of 12,686 compounds or classes, 612 were enriched in TRD-associated genes (FDR $\mathrm{p}<0.05$ ). Significant results included drugs which are currently used in TRD (e.g. lithium and ketamine), confirming the rationale of this approach. Interesting molecules included modulators of inflammation, renin-angiotensin system, proliferator-activated receptor agonists, glycogen synthase kinase 3 beta inhibitors and the rho associated kinase inhibitor fasudil. Naturally occurring compounds, mostly antioxidant polyphenols, were also identified. Drugs showing enrichment for TRD-associated genes had a higher probability of enrichment for MDD-associated genes compared to those having no TRD-genes enrichment ( $\mathrm{p}<2.2 \mathrm{e}-16)$.

This study identified new potential treatments for TRD using a in silico approach. Further testing of these results may lead to new treatments for TRD.
\end{abstract}

Keywords: treatment-resistant depression; drug repurposing; pharmacogenetics; major depression 


\section{Introduction}

Between $20 \%$ and $30 \%$ of persons with major depressive disorder (MDD) develop treatment-resistant depression (TRD), a condition usually defined as lack of response to at least two different antidepressants (Souery et al., 1999) (Rizvi et al., 2014). TRD is associated with social and occupational impairment, suicidal thoughts, decline of physical health and increased health care utilization (Trivedi et al., 2006) (Souery et al., 2011). Annual costs for health care and lost productivity were estimated to be US $\$ 5,481$ and $\$ 4,048$ higher, respectively, for a patient with TRD versus a patient with treatment-responsive depression (Mrazek et al., 2014).

Finding new effective treatments in TRD has been a challenge. As a matter of fact, almost all the available antidepressants act through the modulation of monoamine reuptake and/or monoamine receptors and patients with TRD tend to respond poorly to these drugs (Harmer et al., 2017). The return to long known compounds with alternative mechanism of action but problematic side effects such as ketamine was chosen since other options with similar effectiveness are lacking (Harmer et al., 2017).

Traditional drug development is a long and expensive process: getting a drug to market currently takes 13-15 years and between US\$2 billion and \$3 billion on average, and the costs are going up, even though the number of drugs approved every year per dollar spent on development has remained flat or decreased for most of the past decade (Nosengo, 2016). Repurposing of existing drugs (approved or during development for any disease) is an alternative approach aiming at skipping the first phases of drug development (pre-clinical phase and safety tests in humans). It was estimated that repositioning a drug costs on average $\$ 300$ million and takes around 6.5 years (Nosengo, 2016). Interestingly, the first drug reported to have antidepressant effects was iproniazid, an antitubercular compound which showed as "side effects" euphoria, psychostimulation, increased appetite, and improved sleep (Hillhouse and Porter, 2015). Serendipity apart, repurposing can be guided by different types of experimental data, for example in vitro cellular assays, animal models, or biomarkers of disease in affected populations. For example, genes associated with a disease may be used to identify potential pharmacological targets, a strategy that seems very promising as selecting genetically supported targets could double the success rate in clinical development (Nelson et al., 2015).

Previous studies used genetic markers of MDD to guide the identification of drugs that may be repurposed for the treatment of this disorder. The overlap between genes associated with MDD and known drug targets suggested some possible mechanisms of action, including dopamine receptor modulation, estrogen receptor modulation, calcium channels modulation and antagonism, acetylcholine receptor M3 antagonism, and histone deacetylase inhibition (So et al., 2019) (Zhao and So, 2019) (Gaspar et al., 2019) (So et al., 2017). However, these studies did not specifically focus on genetic markers of TRD, which may only partially overlap with those of MDD.

The present study aimed to identify new possible pharmacological options for TRD by comparing genes previously associated with this phenotype and known drug targets. We specifically used TRD as phenotype in order to increase the chances to identify drugs that may be effective in this group of patients with MDD who poorly respond to drugs acting through the modulation of monoaminergic neurotransmission. 


\section{Methods}

\subsection{Gene-drug targets databases}

Genes coding for targets of drugs in any phase of development (from pre-clinical to launched), nutraceuticals, proteins and peptides were obtained from three publicly available databases: DrugGene Interaction (DGI) database, Drug Repurposing Hub (DRH) and DrugBank. The DGI database includes a combination of expert curation and text-mining from a number of sources (e.g. therapeutic target database, PharmGKB, ClinicalTrials.gov) (Cotto et al., 2018). This database also included drug classes (e.g. non-steroidal anti-inflammatory drugs). DRH is a manually curated source, compound samples were registered in the Broad compound management system and annotated for a number of characteristics (Corsello et al., 2017). DrugBank is expert curated and includes not only drugs but also proteins, peptides, and nutraceuticals (Wishart et al., 2018).

Drugs and other compounds from these datasets were merged based on their CHEMBL ID or chemical name when CHEMBL ID was not available.

\subsection{Genes associated with treatment-resistant depression}

We selected the gene sets previously demonstrated to predict the risk of TRD in a whole exome sequence and genome-wide association study on 1209 patients with MDD (Fabbri et al., 2020). These included a total of 1715 genes, which are mainly involved in the regulation of cell survival and proliferation, neurodegeneration and immune response. These genes consisted in four groups: 1) genes predicting TRD in patients treated with mixed antidepressants $(n=17) ; 2)$ genes predicting TRD in patients treated with serotonergic antidepressants $(n=83) ; 3)$ genes in pathways predicting TRD in patients treated with mixed antidepressants $(n=216)$; 4) genes in pathways predicting TRD in patients treated with treated with serotonergic antidepressants $(n=1398)$. These four groups were analysed separately since they were obtained in groups of patients treated with drugs having distinct pharmacologic domains or they reflected different prediction approaches (using genes or pathways as predictors of TRD).

\subsection{Statistical analysis}

For each molecule available in the described gene-drug target databases, we performed a hypergeometric test to evaluate if it was enriched in genes associated with TRD in any of the four groups described in paragraph 2.2 and kept the most significant finding when we observed enrichment in more than one of the four gene groups. The hypergeometric test measures the statistical significance of having drawn a sample consisting of a specific number of $\mathrm{k}$ successes (out of $\mathrm{n}$ total draws) from a population of size $\mathrm{N}$ containing $\mathrm{K}$ successes. In this case, $\mathrm{k}$ represents the number of genes targeted by a molecule/drug which are also associated with TRD, $\mathrm{n}$ is the total number of genes associated with TRD, $\mathrm{N}$ is the total number of genes tested and $\mathrm{K}$ is the total number of genes targeted by the molecule/drug. The test was performed using $\mathrm{R}$ cran as follows: phyper( $\mathrm{k}-1, \mathrm{n}, \mathrm{N}-\mathrm{n}, \mathrm{K}$, lower.tail=FALSE) and the Benjamini \& Hochberg false-discovery rate (FDR) correction was applied to account for multiple-testing. We finally compared the significant results with the molecules showing enrichment in genes associated with MDD (considering loci, gene and pathway analyses) in a large genome-wide association study (Wray et al., 2018). The workflow is described in Figure 1. 


\section{Results}

We found 3560 molecules available in at least two databases, while 9126 available in only one; each molecule had on average 3.28 gene targets $(\mathrm{SD}=6.77)$. The number of available molecules in each dataset is reported in Supplementary Table 1.

A total of 612 molecules and 10 classes enriched for TRD-associated genes were identified (FDR $\mathrm{p}<0.05)$ and their annotations are reported in Supplementary Table 2, while a summary description is in Table 1. Molecules showing enrichment for TRD-associated genes had a higher probability of enrichment for MDD-associated genes compared to those having no TRD-genes enrichment $(\mathrm{p}<2.2 \mathrm{e}-$ 16), in line with what expected. Drugs with known therapeutic effect in TRD showed enrichment in TRD-associated genes, such as lithium (FDR p=9.25e-05), tricyclic antidepressants (FDR p=2.68e03) and ketamine (FDR $\mathrm{p}=1.22 \mathrm{e}-02$ ), demonstrating the validity of the approach. TRD-associated genes generally showed higher probability to be druggable than what expected by chance (genes in pathways predicting TRD in patients treated with mixed antidepressants and serotonergic antidepressants: $\mathrm{p}=2.49 \mathrm{e}-12$ and $\mathrm{p}=2.10 \mathrm{e}-105$, respectively; genes predicting TRD in patients treated with mixed antidepressants and serotonergic antidepressants: $\mathrm{p}=0.038$ and $\mathrm{p}=0.61$, respectively). In order to exclude that this result could be caused by a general higher druggability of genes in pathways compared to genes not belonging to known pathways, we extracted random sets of genes having the same size of the tested ones from known pathways 10,000 times. The mean number of druggable genes found in the random pathways was significantly lower compared to the tested pathways (61 and $328, p=0.0078$ and $p=7.27 \mathrm{e}-17$ for those associated with resistance to mixed antidepressants and serotonergic antidepressants, respectively).

The most common mechanisms of action of molecules which targets were enriched in TRDassociated genes were modulation of cell proliferation/survival (31\%), monoamine neurotransmission (14\%) and modulation of inflammation and extracellular matrix (13\%). Not surprisingly, the second group included the highest percentage of drugs approved/studied for the treatment of psychiatric disorders (26\%). Other groups that included drugs approved/studied for psychiatric disorders were modulators of glycogen synthase kinase 3 beta (GSK3), modulators of vasopressin, angiotensin and/or oxytocin, drugs acting on cholinergic neurotransmission and GABAergic/glutamatergic neurotransmission (Table 1), though in some cases there were molecules in an earlier phase of clinical research or still not registered (e.g. pre-clinical studies) for the treatment of psychiatric illnesses (see notes in Supplementary Table 2). An example of this case was represented by peroxisome proliferator-activated receptor (PPAR) agonists and naturally occurring compounds with antioxidant/anti-inflammatory activity (e.g. ellagic acid), as described in detail in the Discussion. The proportion of molecules in the post-marketing phase or phase 2-3 was variable, but it was usually at least $50 \%$ for the drug groups including at least ten molecules (Table 1), therefore providing a quite rich pool of potential candidates that already passed phase 1 of development. 


\section{Discussion}

The present study aimed to identify possible candidate drugs for repositioning in TRD by testing known drug gene targets for enrichment in TRD-associated genes. The results suggested about 600 possible candidate compounds, including not only drugs but also peptides and nutraceuticals. Drugs with indication for the treatment of TRD were included, such as lithium, ketamine and several antidepressants, confirming the rationale of the approach. In terms of mechanisms of action, the largest group was represented by modulators of cell proliferation/survival, in line with the observation that neural survival and neurogenesis are implicated in the pathogenesis of depression (Miller and Hen, 2015). However, this group mostly included drugs studied or approved for the treatment of various types of cancer, working through the inhibition of cellular signalling cascades controlled by growth factor receptors, and this is clearly not a therapeutic option for TRD as it would produce negative rather than beneficial effects. This reflects the main limitation of the present approach: it does not distinguish the direction of the effect (therapeutic or noxious) of drugs which targets are enriched in TRD-associated genes. However, this could be inferred from the mechanisms of drug action, thus the present results can provide meaningful information after proper interpretation. Drugs with interesting mechanisms of action based on the literature and previous evidence of possible antidepressant effects are therefore discussed in the next sections to provide cues on potential new treatments for TRD (Table 2).

\subsection{Renin-angiotensin system modulators}

A total of 22 molecules had this as primary mechanism of action, for example telmisartan, captopril and nelivaptan. The renin-angiotensin system (RAS) does not play a role only in the modulation of the cardiovascular system, but it also has important regulatory functions in the brain. Angiotensin receptors (primarily AT1R) are indeed expressed in the brain where angiotensin II (Ang II) is implicated in multiple pathways related to regulation of the stress response. For example, the activation of AT1R contributes to the release of inflammatory cytokines (e.g. tumour necrosis factor $\alpha$ ), to oxidative and nitrosative stress, and to the increase in the production of corticotrophin-releasing factor (Vian et al., 2017). AT2R is involved in neurodevelopment, extracellular matrix modulation, neuronal regeneration, apoptosis and cellular differentiation, and other components of the RAS system such as ACE2 and angiotensin-(1-7) were demonstrated to play a role in processes relevant to neuroprotection and neurotoxicity (Vian et al., 2017). In animal models, the blockage of Ang II has antidepressant-like and anti-anxiety effects and confirmed the anti-inflammatory and oxidative stress-reducing effects as part of the mechanisms of action of AT1R antagonists and ACE inhibitors (ACEIs) (Vian et al., 2017). Though there are not randomized controlled trials (RCTs) investigating the potential antidepressant effect of these drugs in humans, the results of observational or case control studies suggested that persons exposed to ACEIs have a lower risk of MDD compared to other antihypertensive drug classes (Rathmann et al., 1999) (Williams et al., 2016) (Boal et al., 2016). A recent meta-analysis of eleven studies reported that compared with placebo or other antihypertensive medications, AT1R blockers and ACEIs were associated with improved overall quality of life, increased wellbeing, improved mental health and anxiety domains of quality of life, though no significant difference was found for the depression domain (Brownstein et al., 2018).

\subsection{Glycogen synthase kinase 3 beta (GSK3B) inhibitors}

GSK3B is implicated in the pathogenesis of mood disorders, anxiety, response to reward and in antidepressant action through several mechanisms. One of the mechanisms of action of lithium and 
atypical antipsychotics having indications in mood disorders is the inhibition of GSK3B (Li and Jope, 2010) and GSK3B inhibition is necessary for the rapid antidepressant effects of ketamine in mice (Beurel et al., 2011, p. 3). GSK3B regulates the activity of proteins with mood-regulating functions, such as the transcription factor cyclic AMP response element-binding protein (CREB), $\beta$-catenin, disrupted in schizophrenia 1 (DISC1), serotonin receptors, N-methyl-D-aspartate (NMDA) receptor, inflammatory cytokines; therefore it has an impact on neuroprotective mechanisms, neuroplasticity and stress response (Li and Jope, 2010). Mice with mutations blocking the inhibition of GSK3B and GSK3alpha showed increased susceptibility to both amphetamine-induced hyperactivity and stressinduced depressive-like behaviours, but not altered baseline behaviours, suggesting that insufficient inhibitory serine phosphorylation of GSK3 is a risk factor for developing mood-related behavioural disturbances (Li and Jope, 2010).

Among the compounds which targets were enriched in TRD-associated genes, the selective, potent, ATP-competitive GSK3 inhibitor CHIR99021 was shown to be well-tolerated and significantly ameliorated mood-related behaviours in mice (Pan et al., 2011). SB-415286 and TWS119 were demonstrated to have neuroprotective effects and induce neural differentiation of stem cells (Dill et al., 2008) (Ding et al., 2003). Both alsterpaullone and kenpaullone prevented neuron cell death in response to variety of insults including trophic deprivation, thapsigargin treatment, and mitochondrial stress (Eldar-Finkelman and Martinez, 2011). It has been suggested that GSK3 inhibition may potentiate the synaptogenic and antidepressant-like effects of ketamine and could make effective subthreshold doses of ketamine (Liu et al., 2013).

\subsection{Proliferator-activated receptor agonists and nitric oxide inhibitors}

Proliferator-activated receptor (PPAR) agonists are a class of medications for the treatment of insulin resistance in type 2 diabetes; interestingly, there is a link between insulin resistance and related pathophysiological changes with depressive symptoms. Insulin resistance is indeed associated with pro-inflammatory changes, mitochondria abnormalities, oxidative stress and modifications in the release and reuptake of monoamine neurotransmitters (Kemp et al., 2014). Animal studies demonstrated that PPAR agonists such as pioglitazone have antidepressant-like properties and suggested that the nitric oxide (NO) pathway is partially responsible for this effect (Eissa Ahmed et al., 2009) (Sadaghiani et al., 2011). NO is a gaseous neurotransmitter generated from L-arginine by the enzymes NO synthase (NOS), which are expressed in three isoforms in the brain, neuronal NOS (nNOS), endothelial NOS (eNOS) and inducible NOS (iNOS), with nNOS representing the major source for NO synthesis, anchored in close proximity to N-methyl-d-aspartate (NMDA) receptors. NO plays a role in synaptic homeostasis and exerts various neuromodulatory effects as well as promotes neuronal plasticity. Imbalances in NOS activity have been demonstrated in depression and response to stress; aminoguanidine and other NOS inhibitors were shown to have antidepressant-like effects in animal models of depression (Joca et al., 2019).

PPAR agonists (pioglitazone or rosiglitazone) were shown to have antidepressant effects in four open-label studies and in three out of four RCTs in patients with major depression (Colle et al., 2017). In patients with concomitant metabolic syndrome or related disorders such as abdominal obesity these drugs were reported not only to improve depressive symptoms but also markers of cardiometabolic risk, including insulin resistance and inflammation biomarkers (Kemp et al., 2012) (Kemp et al., 2014). According to these studies, patients with bipolar or unipolar depression who did not respond

to previous pharmacological treatments (treatment-resistant depression) may benefit from pioglitazone or rosiglitazone. Both these drugs are selective for the gamma subtype of PPAR 
(PPAR $\gamma$ ), but also PPAR $\alpha$ modulate antioxidant responses, neurotransmission, neuroinflammation and neurogenesis; as a matter of fact, fenofibrate, a selective agonist of PPAR $\alpha$, had significant antidepressant-like effects in mice via enhancing the hippocampal BDNF system, while PPAR $\alpha$ antagonism blocked the effects of both fenofibrate and fluoxetine (Song et al., 2018). Interestingly, PPAR agonists were identified also in a previous drug repurposing study for MDD (So et al., 2017). A related drug class that may have beneficial effects for the treatment of depressive symptoms in comorbidity with metabolic abnormalities is represented by HMG-CoA reductase inhibitors (statins). Preliminary RCTs have indeed indicated that statins may have adjunctive antidepressant effects when used as add-on treatment to selective serotonin reuptake inhibitors (SSRIs) (Köhler-Forsberg et al., 2017).

\subsection{Modulators of inflammation and immune system}

Several members of this group were previously studied for the treatment of depression as augmentation to antidepressants, such as acetylsalicylic acid, celecoxib and other non-steroidal antiinflammatory drugs that were enriched in TRD-associated genes (Andrade, 2014) (Kopschina Feltes et al., 2017). These drugs act through the inhibition of cyclooxygenases (COXs) that are key enzymes in the production of prostaglandins, implicated in inflammatory response, pain and autonomic functions (Kopschina Feltes et al., 2017).

An alternative mechanism that may be considered for the modulation of inflammation in depression is represented by the inhibition of the p38 mitogen-activated protein (p38-MAPK) signaling pathway. This pathway is activated in response to various stress stimuli, including post-traumatic stress (Lizama et al., 2009) (Peng et al., 2013). Stressed mice subjected to intrahippocampal or intraventricular injections of the p38 inhibitor SB203580, which targets are enriched in TRDassociated genes, exhibited fewer depression- and anxiety-like behaviors (Zhao et al., 2018) (Han et al., 2019). The p38-MAPK pathway modulates a variety of cellular process, but its role in the regulation of neuroinflammation in regions relevant to emotion regulation was proposed as a key contributor to its effects on depressive behaviors (Zhao et al., 2018). Drugs acting through the inhibition of p38-MAPK could also have pro-cognitive effects as shown for neflamapimod (ArduraFabregat et al., 2017).

Inhibitors of pro-inflammatory cytokines are a further group of drugs with potential application for the treatment of TRD. An example is anakinra (an interleukin 1 receptor antagonist) which is approved for the treatment of rheumatoid arthritis and it was associated with an improvement in mood in patients with this disorder (Koo and Duman, 2009).

Several of the identified drugs are modulators of matrix metalloproteinases (MMPs), which may play a role in antidepressant effects. MMPs target various substrates in the brain, and they modulate adaptive brain plasticity, inflammation and cytotoxicity through the modelling of the perineuronal net. Various antidepressant medications increase the expression of MMPs, which in turn may increase pyramidal cell dendritic arborization and spine formation (Alaiyed and Conant, 2019). However, the large range of processes regulated by MMPs, depending from MMPs subtypes and localization, makes them a non-easy pharmacological target for depression. None of the identified molecules were studied for the treatment of depression, apart from doxycycline, which at subantimicrobial doses is an inhibitor of MMPs and showed antidepressant-like effects in lipopolysaccharide-induced depressive behavior in mice (Mello et al., 2013). Doxycycline was among the identified drugs in a previous drug repurposing study for MDD (So et al., 2017). 
Recently, the inhibition of rapamycin complex 1 (mTORC1) by pre-treatment with rapamycin in patients receiving ketamine was unexpectedly shown to prolong the antidepressant effects of ketamine rather than inhibiting them as suggested by animal models. One of the possible mechanisms explaining this finding may consist in the anti-inflammatory effect of rapamycin via mTORC1 inhibition that may protect ketamine-induced newly made synapses from elimination (Abdallah et al., 2020).

\subsection{Modulators of GABAergic and glutamatergic neurotransmission}

Within this group, ketamine has already strong evidence of efficacy in TRD (Kraus et al., 2019). Other glutamate receptor antagonists which targets were enriched in TRD-associated genes were dextromethorphan and spermidine. Spermidine (as well as spermine and agmatine) is a short, positively charged aliphatic amine that have fundamental roles in homeostatic mechanisms, including the modulation of NMDA and $\alpha$-amino-3-hydroxy-5-methyl-4-isoxazolepropionic acid (AMPA) glutamatergic receptors and therefore neuronal excitability. Polyamine levels have been demonstrated to increase during stress, a phenomenon called the polyamine stress response, and they have been implicated in MDD and suicide (Limon et al., 2016). Spermidine is also involved in the regulation of aging and external supply of polyamines may protect against age-related memory loss, representing a possible therapeutic intervention that is currently under investigation (Wirth et al., 2019). Dextromethorphan is a medication approved as cough suppressant, however its effect on NMDA, sigma-1 and mu opioid receptors as well as the serotonin and noradrenaline transporters made it interesting as potential rapid-acting antidepressant (Lauterbach, 2011). A case report and an openlabel trial of dextromethorphan in TRD showed good tolerability and preliminary evidence of efficacy (Lauterbach, 2016) (Murrough et al., 2017). The limited bioavailability of dextromethorphan and the risk of subtherapeutic doses led to the design of AVP-786, an oral formulation that combines dextromethorphan hydrobromide and quinidine sulfate to increase the bioavailability of the compound by decreasing the metabolism through CYP2D6. A phase two RCT aiming to evaluate the efficacy of AVP-786 in TRD has been completed in 2016, but the results are still not published (ClinicalTrials.gov Identifier: NCT02153502).

Modulators of L-glutamine, the precursor of glutamate and GABA, are also potentially interesting molecules for TRD. Perturbations in glutamine levels may alter neuronal-astrocytic interactions (Struzyńska and Sulkowski, 2004) and glutamine deficiency in the pre-frontal cortex was reported to increase depressive-like behaviors in mice (Lee et al., 2013). Inhibition of glutamate synthetase by methionine sulfoximine decreased glutamate and glutamine levels and increased depressive behaviors, a condition that was reversed by exogenous glutamine (Son et al., 2018). Changes in the glutamine/glutamate ratio were associated with the efficacy of ketamine and other compounds such as cytidine in improving depressive symptoms (Yoon et al., 2009) (Li et al., 2017).

Among modulators of GABAergic neurotransmission, tiagabine and vigabatrin were enriched in TRD-associated genes. Vigabatrin was shown to have antiepileptogenic and antidepressant properties in an animal model of depression and comorbid epilepsy (Russo et al., 2011), but it has no evidence of antidepressant effects in humans. Tiagabine has known effects as mood stabilizer, antidepressant and anxiolytic-like effects that may partly dependent from a modulation of the hypothalamic pituitary adrenal (HPA) axis in animal models, and it has been proven effective in patients with generalized anxiety disorder (Sałat et al., 2015) (Thoeringer et al., 2010) (Strawn et al., 2018). 


\subsection{Natural compounds}

The glutathione precursor N-acetyl-1-cysteine (NAC) was included in this group, a compound studied as add on to antidepressants in TRD for its known positive effects on neuro-inflammation, glutamate neuronal activity and neurogenesis (Yang et al., 2018).

Several polyphenolic compounds with antioxidant properties (flavonoids) were enriched in TRDassociated genes; these included ellagic acid, epigallocatechin gallate, quercetin, resveratrol, clove oil and sho-saiko-to (which main component is baicalein in wogon (Makino et al., 2006)). Ellagic acid occurs largely in plants such as raspberries, the stem and bark of eucalyptus species and nuts, while epigallocatechin gallate and quercetin are found in green/black tea, the latter and resveratrol in red wine (Girish et al., 2012) (Rothenberg and Zhang, 2019) (Hritcu et al., 2017) (Zhu et al., 2019). Bioflavonoids have been reported to have antioxidant, anti-inflammatory, cardio-protective and anticancer properties. Antidepressant-like effects were observed in mice and they were linked to the modulation of the monoaminergic system (particularly, increase of serotonin and norepinephrine availability in the synaptic cleft), increased BDNF level in mice hippocampus, NOS inhibition, restoration of HPA dysfunctions and suppression of the microglial neuroinflammatory response (Girish et al., 2012) (Bedel et al., 2018) (Dhingra and Chhillar, 2012) (Rothenberg and Zhang, 2019) (Hritcu et al., 2017) (Zhu et al., 2019). Both resveratrol and ellagic acid were identified also in a previous drug repurposing study for MDD (So et al., 2019).

Clove oil (Syzygium aromaticum) is a traditional spice that has been used for food preservation and it has several active constituents, including phenolic compounds, sesquiterpenes, and monoterpenes. It has documented pro-cognitive, analgesic, cardio-protective, anti-inflammatory and antidepressantlike effects; the latter were attributed to the inhibition of monoamine oxidase A by the active component eugenol (El-Saber Batiha et al., 2020).

Sho-saiko-to (or xiăocháihútāng, XCHT) is a traditional Chinese medicine which was first recorded in 150-219 AD to cure "Shaoyang syndrome", which included depressive symptoms such as upset and anepithymia. This compound was demonstrated to have antidepressant-like effects in animal models of depression by enhancing the serotoninergic system in the prefrontal cortex and hippocampus (Su et al., 2014).

Finally, zinc and selenium targets were also enriched in TRD-associated genes. These are essential trace elements involved in antioxidant and other cellular processes relevant to brain metabolism. Zinc deficiency has been associated with depression in a meta-analysis of 17 observational studies and RCTs have demonstrated decreases in depressive symptoms when supplementing antidepressants with zinc compared to antidepressants alone (Wang et al., 2018). Possible mechanisms involved in this positive effect include the modulation of NMDA receptors, HPA axis, zinc-sensing GPR39 receptors, anti-inflammatory and antioxidant properties and NOS inhibition (Wang et al., 2018). Selenium deficiency was associated with decreased BDNF concentrations and supplementation of selenium showed antidepressant-like effects in animal models of depression, though studies in humans provided inconsistent results (Wang et al., 2018).

Therefore, the evaluation of possible deficits of these elements in patients with depression is particularly relevant. Zinc is primarily consumed through red meats and seafood, diets that limit the consumption of these foods (e.g., vegetarianism, veganism) may alter serum zinc levels. Selenium deficiency often results from suboptimal presence in regional soil, making selenium deficiency often an endemic issue (Wang et al., 2018). 


\subsection{Other mechanisms}

Modulation of estrogen and androgen receptors has been studied as a possible strategy to treat depressive symptoms and has emerged in previous drug repurposing studies (Gaspar et al., 2019), though it should be considered only in selected groups of patients (peri- or post-menopausal women (Morgan et al., 2005), hypogonadal men (Amiaz and Seidman, 2008)). Among the studied compounds, the neurosteroid dehydroepiandrosterone (DHEA) has emotion regulatory effects and plasma levels were associated with remission in MDD (Hough et al., 2017); DHEA was reported also by a previous drug repurposing study for MDD (So et al., 2019).

The therapeutic potential of cannabidiol in MDD emerged from this study as well as in a previous repurposing study (So et al., 2019). Cannabidiol, a non-psychotomimetic component of Cannabis sativa, shows both rapid and sustained antidepressant-like effects in animal models of depression, effects which were associated with an increase in BDNF levels in both prefrontal cortex and hippocampus (Sales et al., 2019) (Silote et al., 2019). A possible underlying mechanism is the modulation of serotonergic and glutamatergic cortical signaling through a 5-HT1A receptordependent activity (Linge et al., 2016).

The modulation of dopaminergic receptors is another pharmacological mechanism which has been long studied for the treatment of MDD and suggested by previous drug repositioning papers (Gaspar et al., 2019)(So et al., 2017). In this group, pramipexole is an interesting option. It is s a non-ergot dopamine agonist with high affinity for the D2, D3 and D4 dopamine receptors, approved for the treatment of Parkinson's disease and restless legs syndrome. Evidence of antidepressant efficacy compared to placebo was reported in a meta-analysis of five RCTs (Tundo et al., 2019) and one RCT showed superior efficacy of pramipexole augmentation to antidepressants vs. augmentation with placebo in TRD (Cusin et al., 2013).

Less investigated mechanisms of action that may be promising for the treatment of TRD include rhokinase (ROCK) inhibitors, poly(ADP-ribose) polymerase (PARP) inhibitors and TGF beta agonists. ROCK inhibitors (e.g. fasudil) have rapid antidepressant-like effects in mice, comparable to ketamine, which is presumably linked to the promotion of activity-dependent dendritic spine pruning or spine head enlargement; ROCK indeed inhibits cofilin-mediated actin cycling, the process of change in size and shape of dendrites controlled by actin filaments (Shapiro et al., 2019). Compared to this mechanism which appears particularly innovative, the other mentioned ones involve alternative pathways to induce anti-inflammatory and/or neuroprotective/antioxidant effects which showed promising results in animal models of depression (Ordway et al., 2017) (Zhang et al., 2020).

\subsection{Conclusions}

The identification of effective and well-tolerated drugs with antidepressant effects in TRD is a challenging but vital task to reduce the burden of MDD to individuals and society. This study explored potential mechanisms alternative to the inhibition of monoamines reuptake using the results of a pharmacogenomic study and comparisons with the previous literature. Though the available evidence of antidepressant efficacy of the proposed compounds is variable, we provided useful information for future studies that may lead to innovative treatments for TRD. 


\section{Conflicts of interest}

Dr. Souery D. has received grant/research support from GlaxoSmithKline and Lundbeck; has served as a consultant or on advisory boards for AstraZeneca, Bristol-Myers Squibb, Eli Lilly, Janssen and Lundbeck. Prof. Montgomery S. has been a consultant or served on Advisory boards: AstraZeneca, Bristol Myers Squibb, Forest, Johnson \& Johnson, Leo, Lundbeck, Medelink, Neurim, Pierre Fabre, Richter. Prof. Kasper S. received grants/research support, consulting fees and/or honoraria within the last three years from Angelini, AOP Orphan Pharmaceuticals AG, Celegne GmbH, Eli Lilly, JanssenCilag Pharma GmbH, KRKA-Pharma, Lundbeck A/S, Mundipharma, Neuraxpharm, Pfizer, Sanofi, Schwabe, Servier, Shire, Sumitomo Dainippon Pharma Co. Ltd. and Takeda. Prof. Zohar J. has received grant/research support from Lundbeck, Servier, Brainsway and Pfizer, has served as a consultant or on advisory boards for Servier, Pfizer, Abbott, Lilly, Actelion, AstraZeneca and Roche, and has served on speakers' bureaus for Lundbeck, Roch, Lilly, Servier, Pfizer and Abbott. Prof. Mendlewicz J. is a member of the Board of the Lundbeck International Neuroscience Foundation and of Advisory Board of Servier. Prof. Serretti A. is or has been consultant/speaker for: Abbott, Abbvie, Angelini, Astra Zeneca, Clinical Data, Boheringer, Bristol Myers Squibb, Eli Lilly, GlaxoSmithKline, Innovapharma, Italfarmaco, Janssen, Lundbeck, Naurex, Pfizer, Polifarma, Sanofi, Servier. Cathryn Lewis is a member of the R\&D SAB of Myriad Neuroscience. The other authors declare no conflict of interest.

\section{Funding}

Chiara Fabbri is funded by Fondazione Umberto Veronesi (https://www.fondazioneveronesi.it). Cathryn Lewis and Chiara Fabbri are part-funded by the National Institute for Health Research (NIHR) Biomedical Research Centre at South London and Maudsley NHS Foundation Trust and King's College London.

\section{References}

Abdallah, C.G., Averill, L.A., Gueorguieva, R., Goktas, S., Purohit, P., Ranganathan, M., Sherif, M., Ahn, K.-H., D’Souza, D.C., Formica, R., Southwick, S.M., Duman, R.S., Sanacora, G., Krystal, J.H., 2020. Modulation of the antidepressant effects of ketamine by the mTORC1 inhibitor rapamycin. Neuropsychopharmacol. Off. Publ. Am. Coll. Neuropsychopharmacol. 45, 990-997. https://doi.org/10.1038/s41386-020-0644-9

Alaiyed, S., Conant, K., 2019. A Role for Matrix Metalloproteases in Antidepressant Efficacy. Front. Mol. Neurosci. 12, 117. https://doi.org/10.3389/fnmol.2019.00117

Amiaz, R., Seidman, S.N., 2008. Testosterone and depression in men. Curr. Opin. Endocrinol. Diabetes Obes. 15, 278-283. https://doi.org/10.1097/MED.0b013e3282fc27eb

Andrade, C., 2014. Antidepressant augmentation with anti-inflammatory agents. J. Clin. Psychiatry 75, 975-977. https://doi.org/10.4088/JCP.14f09432

Ardura-Fabregat, A., Boddeke, E.W.G.M., Boza-Serrano, A., Brioschi, S., Castro-Gomez, S., Ceyzériat, K., Dansokho, C., Dierkes, T., Gelders, G., Heneka, M.T., Hoeijmakers, L., Hoffmann, A., Iaccarino, L., Jahnert, S., Kuhbandner, K., Landreth, G., Lonnemann, N., Löschmann, P.A., McManus, R.M., Paulus, A., Reemst, K., Sanchez-Caro, J.M., Tiberi, A., Van der Perren, A., Vautheny, A., Venegas, C., Webers, A., Weydt, P., Wijasa, T.S., Xiang, X., Yang, Y., 2017. Targeting Neuroinflammation to Treat Alzheimer's Disease. CNS Drugs 31, 1057-1082. https://doi.org/10.1007/s40263-017-0483-3

Bedel, H.A., Kencebay Manas, C., Özbey, G., Usta, C., 2018. The antidepressant-like activity of ellagic acid and its effect on hippocampal brain derived neurotrophic factor levels in mouse 
depression models. Nat $\quad$ Prod. Res. 32, 2932-2935. https://doi.org/10.1080/14786419.2017.1385021

Beurel, E., Song, L., Jope, R.S., 2011. Inhibition of glycogen synthase kinase-3 is necessary for the rapid antidepressant effect of ketamine in mice. Mol. Psychiatry 16, 1068-1070. https://doi.org/10.1038/mp.2011.47

Boal, A.H., Smith, D.J., McCallum, L., Muir, S., Touyz, R.M., Dominiczak, A.F., Padmanabhan, S., 2016. Monotherapy With Major Antihypertensive Drug Classes and Risk of Hospital Admissions for Mood Disorders. Hypertens. Dallas Tex 1979 68, 1132-1138. https://doi.org/10.1161/HYPERTENSIONAHA.116.08188

Brownstein, D.J., Salagre, E., Köhler, C., Stubbs, B., Vian, J., Pereira, C., Chavarria, V., Karmakar, C., Turner, A., Quevedo, J., Carvalho, A.F., Berk, M., Fernandes, B.S., 2018. Blockade of the angiotensin system improves mental health domain of quality of life: A meta-analysis of randomized clinical trials. Aust. N. Z. J. Psychiatry 52, 24-38. https://doi.org/10.1177/0004867417721654

Colle, R., de Larminat, D., Rotenberg, S., Hozer, F., Hardy, P., Verstuyft, C., Fève, B., Corruble, E., 2017. PPAR- $\gamma$ Agonists for the Treatment of Major Depression: A Review. Pharmacopsychiatry 50, 49-55. https://doi.org/10.1055/s-0042-120120

Corsello, S.M., Bittker, J.A., Liu, Z., Gould, J., McCarren, P., Hirschman, J.E., Johnston, S.E., Vrcic, A., Wong, B., Khan, M., Asiedu, J., Narayan, R., Mader, C.C., Subramanian, A., Golub, T.R., 2017. The Drug Repurposing Hub: a next-generation drug library and information resource. Nat. Med. 23, 405-408. https://doi.org/10.1038/nm.4306

Cotto, K.C., Wagner, A.H., Feng, Y.-Y., Kiwala, S., Coffman, A.C., Spies, G., Wollam, A., Spies, N.C., Griffith, O.L., Griffith, M., 2018. DGIdb 3.0: a redesign and expansion of the druggene interaction database. Nucleic Acids Res. 46, D1068-D1073. https://doi.org/10.1093/nar/gkx1143

Cusin, C., Iovieno, N., Iosifescu, D.V., Nierenberg, A.A., Fava, M., Rush, A.J., Perlis, R.H., 2013. A randomized, double-blind, placebo-controlled trial of pramipexole augmentation in treatmentresistant major depressive disorder. J. Clin. Psychiatry 74, e636-641. https://doi.org/10.4088/JCP.12m08093

Dhingra, D., Chhillar, R., 2012. Antidepressant-like activity of ellagic acid in unstressed and acute immobilization-induced stressed mice. Pharmacol. Rep. PR 64, 796-807. https://doi.org/10.1016/s1734-1140(12)70875-7

Dill, J., Wang, H., Zhou, F., Li, S., 2008. Inactivation of glycogen synthase kinase 3 promotes axonal growth and recovery in the CNS. J. Neurosci. Off. J. Soc. Neurosci. 28, 8914-8928. https://doi.org/10.1523/JNEUROSCI.1178-08.2008

Ding, S., Wu, T.Y.H., Brinker, A., Peters, E.C., Hur, W., Gray, N.S., Schultz, P.G., 2003. Synthetic small molecules that control stem cell fate. Proc. Natl. Acad. Sci. U. S. A. 100, 7632-7637. https://doi.org/10.1073/pnas.0732087100

Duque-Wilckens, N., Steinman, M.Q., Busnelli, M., Chini, B., Yokoyama, S., Pham, M., Laredo, S.A., Hao, R., Perkeybile, A.M., Minie, V.A., Tan, P.B., Bales, K.L., Trainor, B.C., 2018. Oxytocin Receptors in the Anteromedial Bed Nucleus of the Stria Terminalis Promote StressInduced Social Avoidance in Female California Mice. Biol. Psychiatry 83, 203-213. https://doi.org/10.1016/j.biopsych.2017.08.024

Eissa Ahmed, A.A., Al-Rasheed, Nawal Mohammed, Al-Rasheed, Nouf Mohammed, 2009. Antidepressant-like effects of rosiglitazone, a PPAR $\gamma$ agonist, in the rat forced swim and mouse tail suspension tests. Behav. Pharmacol. 20, 635-642. https://doi.org/10.1097/FBP.0b013e328331b9bf

Eldar-Finkelman, H., Martinez, A., 2011. GSK-3 Inhibitors: Preclinical and Clinical Focus on CNS. Front. Mol. Neurosci. 4, 32. https://doi.org/10.3389/fnmol.2011.00032

El-Saber Batiha, G., Alkazmi, L.M., Wasef, L.G., Beshbishy, A.M., Nadwa, E.H., Rashwan, E.K., 2020. Syzygium aromaticum L. (Myrtaceae): Traditional Uses, Bioactive Chemical 
Constituents, Pharmacological and Toxicological Activities. Biomolecules 10, 202. https://doi.org/10.3390/biom10020202

Fabbri, C., Kasper, S., Kautzky, A., Zohar, J., Souery, D., Montgomery, S., Albani, D., Forloni, G., Ferentinos, P., Rujescu, D., Mendlewicz, J., Uher, R., Lewis, C.M., Serretti, A., 2020. A polygenic predictor of treatment-resistant depression using whole exome sequencing and genome-wide genotyping. Transl. Psychiatry 10, 50. https://doi.org/10.1038/s41398-020$0738-5$

Gaspar, H.A., Gerring, Z., Hübel, C., Major Depressive Disorder Working Group of the Psychiatric Genomics Consortium, Middeldorp, C.M., Derks, E.M., Breen, G., 2019. Using genetic drugtarget networks to develop new drug hypotheses for major depressive disorder. Transl. Psychiatry 9, 117. https://doi.org/10.1038/s41398-019-0451-4

Girish, C., Raj, V., Arya, J., Balakrishnan, S., 2012. Evidence for the involvement of the monoaminergic system, but not the opioid system in the antidepressant-like activity of ellagic acid in mice. Eur. J. Pharmacol. 682, 118-125. https://doi.org/10.1016/j.ejphar.2012.02.034

Han, Q.-Q., Huang, H.-J., Wang, Y.-L., Yang, L., Pilot, A., Zhu, X.-C., Yu, R., Wang, J., Chen, X.R., Liu, Q., Li, B., Wu, G.-C., Yu, J., 2019. Ghrelin exhibited antidepressant and anxiolytic effect via the p38-MAPK signaling pathway in hippocampus. Prog. Neuropsychopharmacol. Biol. Psychiatry 93, 11-20. https://doi.org/10.1016/j.pnpbp.2019.02.013

Harmer, C.J., Duman, R.S., Cowen, P.J., 2017. How do antidepressants work? New perspectives for refining future treatment approaches. Lancet Psychiatry 4, 409-418. https://doi.org/10.1016/S2215-0366(17)30015-9

Hillhouse, T.M., Porter, J.H., 2015. A brief history of the development of antidepressant drugs: From monoamines to glutamate. Exp. Clin. Psychopharmacol. 23, 1-21. https://doi.org/10.1037/a0038550

Hough, C.M., Lindqvist, D., Epel, E.S., Denis, M.S., Reus, V.I., Bersani, F.S., Rosser, R., Mahan, L., Burke, H.M., Wolkowitz, O.M., Mellon, S.H., 2017. Higher serum DHEA concentrations before and after SSRI treatment are associated with remission of major depression. Psychoneuroendocrinology 77, 122-130. https://doi.org/10.1016/j.psyneuen.2016.11.035

Hritcu, L., Ionita, R., Postu, P.A., Gupta, G.K., Turkez, H., Lima, T.C., Carvalho, C.U.S., de Sousa, D.P., 2017. Antidepressant Flavonoids and Their Relationship with Oxidative Stress. Oxid. Med. Cell. Longev. 2017, 1-18. https://doi.org/10.1155/2017/5762172

Joca, S.R.L., Sartim, A.G., Roncalho, A.L., Diniz, C.F.A., Wegener, G., 2019. Nitric oxide signalling and antidepressant action revisited. Cell Tissue Res. 377, 45-58. https://doi.org/10.1007/s00441-018-02987-4

Kemp, D.E., Ismail-Beigi, F., Ganocy, S.J., Conroy, C., Gao, K., Obral, S., Fein, E., Findling, R.L., Calabrese, J.R., 2012. Use of insulin sensitizers for the treatment of major depressive disorder: a pilot study of pioglitazone for major depression accompanied by abdominal obesity. $\mathrm{J}$. Affect. Disord. 136, 1164-1173. https://doi.org/10.1016/j.jad.2011.06.033

Kemp, D.E., Schinagle, M., Gao, K., Conroy, C., Ganocy, S.J., Ismail-Beigi, F., Calabrese, J.R., 2014. PPAR- $\gamma$ agonism as a modulator of mood: proof-of-concept for pioglitazone in bipolar depression. CNS Drugs 28, 571-581. https://doi.org/10.1007/s40263-014-0158-2

Köhler-Forsberg, O., Gasse, C., Berk, M., Østergaard, S.D., 2017. Do Statins Have Antidepressant Effects? CNS Drugs 31, 335-343. https://doi.org/10.1007/s40263-017-0422-3

Koo, J.W., Duman, R.S., 2009. Evidence for IL-1 receptor blockade as a therapeutic strategy for the treatment of depression. Curr. Opin. Investig. Drugs Lond. Engl. 2000 10, 664-671.

Kopschina Feltes, P., Doorduin, J., Klein, H.C., Juárez-Orozco, L.E., Dierckx, R.A., MoriguchiJeckel, C.M., de Vries, E.F., 2017. Anti-inflammatory treatment for major depressive disorder: implications for patients with an elevated immune profile and non-responders to standard antidepressant therapy. J. Psychopharmacol. Oxf. Engl. 31, 1149-1165. https://doi.org/10.1177/0269881117711708 
Kraus, C., Kadriu, B., Lanzenberger, R., Zarate, C.A., Kasper, S., 2019. Prognosis and improved outcomes in major depression: a review. Transl. Psychiatry 9, 127. https://doi.org/10.1038/s41398-019-0460-3

Lauterbach, E.C., 2016. Treatment Resistant Depression with Loss of Antidepressant Response: Rapid-Acting Antidepressant Action of Dextromethorphan, A Possible Treatment Bridging Molecule. Psychopharmacol. Bull. 46, 53-58.

Lauterbach, E.C., 2011. Dextromethorphan as a potential rapid-acting antidepressant. Med. Hypotheses 76, 717-719. https://doi.org/10.1016/j.mehy.2011.02.003

Lee, Y., Son, H., Kim, G., Kim, S., Lee, D.H., Roh, G.S., Kang, S.S., Cho, G.J., Choi, W.S., Kim, H.J., 2013. Glutamine deficiency in the prefrontal cortex increases depressive-like behaviours in male mice. J. Psychiatry Neurosci. JPN 38, 183-191. https://doi.org/10.1503/jpn.120024

Li, M., Demenescu, L.R., Colic, L., Metzger, C.D., Heinze, H.-J., Steiner, J., Speck, O., Fejtova, A., Salvadore, G., Walter, M., 2017. Temporal Dynamics of Antidepressant Ketamine Effects on Glutamine Cycling Follow Regional Fingerprints of AMPA and NMDA Receptor Densities. Neuropsychopharmacology 42, 1201-1209. https://doi.org/10.1038/npp.2016.184

Li, X., Jope, R.S., 2010. Is glycogen synthase kinase-3 a central modulator in mood regulation? Neuropsychopharmacol. Off. Publ. Am. Coll. Neuropsychopharmacol. 35, 2143-2154. https://doi.org/10.1038/npp.2010.105

Limon, A., Mamdani, F., Hjelm, B.E., Vawter, M.P., Sequeira, A., 2016. Targets of polyamine dysregulation in major depression and suicide: Activity-dependent feedback, excitability, and neurotransmission. Neurosci. Biobehav. Rev. 60-91. https://doi.org/10.1016/j.neubiorev.2016.04.010

Linge, R., Jiménez-Sánchez, L., Campa, L., Pilar-Cuéllar, F., Vidal, R., Pazos, A., Adell, A., Díaz, Á., 2016. Cannabidiol induces rapid-acting antidepressant-like effects and enhances cortical 5-HT/glutamate neurotransmission: role of 5-HT1A receptors. Neuropharmacology 103, 1626. https://doi.org/10.1016/j.neuropharm.2015.12.017

Liu, R.-J., Fuchikami, M., Dwyer, J.M., Lepack, A.E., Duman, R.S., Aghajanian, G.K., 2013. GSK3 inhibition potentiates the synaptogenic and antidepressant-like effects of subthreshold doses of ketamine. Neuropsychopharmacol. Off. Publ. Am. Coll. Neuropsychopharmacol. 38, 2268-2277. https://doi.org/10.1038/npp.2013.128

Lizama, C., Lagos, C.F., Lagos-Cabré, R., Cantuarias, L., Rivera, F., Huenchuñir, P., Pérez-Acle, T., Carrión, F., Moreno, R.D., 2009. Calpain inhibitors prevent p38 MAPK activation and germ cell apoptosis after heat stress in pubertal rat testes. J. Cell. Physiol. 221, 296-305. https://doi.org/10.1002/jcp.21868

Makino, T., Tsubouchi, R., Murakami, K., Haneda, M., Yoshino, M., 2006. Generation of Reactive Oxygen Species and Induction of Apoptosis of HL60 Cells by Ingredients of Traditional Herbal Medicine, Sho-saiko-to. Basic Htmlent Glyphamp Asciiamp Clin. Pharmacol. Htmlent Glyphamp Asciiamp Toxicol. 98, 401-405. https://doi.org/10.1111/j.17427843.2006.pto_328.x

Mello, B.S.F., Monte, A.S., McIntyre, R.S., Soczynska, J.K., Custódio, C.S., Cordeiro, R.C., Chaves, J.H., Vasconcelos, S.M.M., Nobre, H.V., Florenço de Sousa, F.C., Hyphantis, T.N., Carvalho, A.F., Macêdo, D.S., 2013. Effects of doxycycline on depressive-like behavior in mice after lipopolysaccharide (LPS) administration. J. Psychiatr. Res. 47, 1521-1529. https://doi.org/10.1016/j.jpsychires.2013.06.008

Miller, B.R., Hen, R., 2015. The current state of the neurogenic theory of depression and anxiety. Curr. Opin. Neurobiol. 30, 51-58. https://doi.org/10.1016/j.conb.2014.08.012

Morgan, M.L., Cook, I.A., Rapkin, A.J., Leuchter, A.F., 2005. Estrogen augmentation of antidepressants in perimenopausal depression: a pilot study. J. Clin. Psychiatry 66, 774-780. https://doi.org/10.4088/jcp.v66n0617 
Mrazek, D.A., Hornberger, J.C., Altar, C.A., Degtiar, I., 2014. A review of the clinical, economic, and societal burden of treatment-resistant depression: 1996-2013. Psychiatr. Serv. Wash. DC 65, 977-987. https://doi.org/10.1176/appi.ps.201300059

Murrough, J.W., Wade, E., Sayed, S., Ahle, G., Kiraly, D.D., Welch, A., Collins, K.A., Soleimani, L., Iosifescu, D.V., Charney, D.S., 2017. Dextromethorphan/quinidine pharmacotherapy in patients with treatment resistant depression: A proof of concept clinical trial. J. Affect. Disord. 218, 277-283. https://doi.org/10.1016/j.jad.2017.04.072

Nelson, M.R., Tipney, H., Painter, J.L., Shen, J., Nicoletti, P., Shen, Y., Floratos, A., Sham, P.C., Li, M.J., Wang, J., Cardon, L.R., Whittaker, J.C., Sanseau, P., 2015. The support of human genetic evidence for approved drug indications. Nat. Genet. 47, 856-860. https://doi.org/10.1038/ng.3314

Nosengo, N., 2016. Can you teach old drugs new tricks? Nature 534, 314-316. https://doi.org/10.1038/534314a

Ordway, G.A., Szebeni, A., Hernandez, L.J., Crawford, J.D., Szebeni, K., Chandley, M.J., Burgess, K.C., Miller, C., Bakkalbasi, E., Brown, R.W., 2017. Antidepressant-Like Actions of Inhibitors of Poly(ADP-Ribose) Polymerase in Rodent Models. Int. J. Neuropsychopharmacol. 20, 994-1004. https://doi.org/10.1093/ijnp/pyx068

Pan, J.Q., Lewis, M.C., Ketterman, J.K., Clore, E.L., Riley, M., Richards, K.R., Berry-Scott, E., Liu, X., Wagner, F.F., Holson, E.B., Neve, R.L., Biechele, T.L., Moon, R.T., Scolnick, E.M., Petryshen, T.L., Haggarty, S.J., 2011. AKT kinase activity is required for lithium to modulate mood-related behaviors in mice. Neuropsychopharmacol. Off. Publ. Am. Coll. Neuropsychopharmacol. 36, 1397-1411. https://doi.org/10.1038/npp.2011.24

Peng, Z., Wang, H., Zhang, R., Chen, Y., Xue, F., Nie, H., Chen, Y., Wu, D., Wang, Y., Wang, H., Tan, Q., 2013. Gastrodin ameliorates anxiety-like behaviors and inhibits IL-1beta level and p38 MAPK phosphorylation of hippocampus in the rat model of posttraumatic stress disorder. Physiol. Res. 62, 537-545.

Rathmann, W., Haastert, B., Roseman, J.M., Giani, G., 1999. Cardiovascular drug prescriptions and risk of depression in diabetic patients. J. Clin. Epidemiol. 52, 1103-1109. https://doi.org/10.1016/s0895-4356(99)00082-7

Rizvi, S.J., Grima, E., Tan, M., Rotzinger, S., Lin, P., Mcintyre, R.S., Kennedy, S.H., 2014. Treatment-resistant depression in primary care across Canada. Can. J. Psychiatry Rev. Can. Psychiatr. 59, 349-357. https://doi.org/10.1177/070674371405900702

Rothenberg, D.O., Zhang, L., 2019. Mechanisms Underlying the Anti-Depressive Effects of Regular Tea Consumption. Nutrients 11, 1361. https://doi.org/10.3390/nu11061361

Russo, E., Citraro, R., Scicchitano, F., Urzino, A., Marra, R., Rispoli, V., De Sarro, G., 2011. Vigabatrin has antiepileptogenic and antidepressant effects in an animal model of epilepsy and depression comorbidity. Behav. Brain Res. 225, 373-376. https://doi.org/10.1016/j.bbr.2011.07.030

Sadaghiani, M.S., Javadi-Paydar, M., Gharedaghi, M.H., Fard, Y.Y., Dehpour, A.R., 2011. Antidepressant-like effect of pioglitazone in the forced swimming test in mice: the role of PPAR-gamma receptor and nitric oxide pathway. Behav. Brain Res. 224, 336-343. https://doi.org/10.1016/j.bbr.2011.06.011

Sałat, K., Podkowa, A., Kowalczyk, P., Kulig, K., Dziubina, A., Filipek, B., Librowski, T., 2015. Anticonvulsant active inhibitor of GABA transporter subtype 1, tiagabine, with activity in mouse models of anxiety, pain and depression. Pharmacol. Rep. PR 67, 465-472. https://doi.org/10.1016/j.pharep.2014.11.003

Sales, A.J., Fogaça, M.V., Sartim, A.G., Pereira, V.S., Wegener, G., Guimarães, F.S., Joca, S.R.L., 2019. Cannabidiol Induces Rapid and Sustained Antidepressant-Like Effects Through Increased BDNF Signaling and Synaptogenesis in the Prefrontal Cortex. Mol. Neurobiol. 56, 1070-1081. https://doi.org/10.1007/s12035-018-1143-4 
Shapiro, L.P., Kietzman, H.W., Guo, J., Rainnie, D.G., Gourley, S.L., 2019. Rho-kinase inhibition has antidepressant-like efficacy and expedites dendritic spine pruning in adolescent mice. Neurobiol. Dis. 124, 520-530. https://doi.org/10.1016/j.nbd.2018.12.015

Silote, G.P., Sartim, A., Sales, A., Eskelund, A., Guimarães, F.S., Wegener, G., Joca, S., 2019. Emerging evidence for the antidepressant effect of cannabidiol and the underlying molecular $\begin{array}{lllll}\text { mechanisms. } & \text { J. } & \text { Chem. }\end{array}$ https://doi.org/10.1016/j.jchemneu.2019.04.006

So, H.-C., Chau, C.K.-L., Chiu, W.-T., Ho, K.-S., Lo, C.-P., Yim, S.H.-Y., Sham, P.-C., 2017. Analysis of genome-wide association data highlights candidates for drug repositioning in psychiatry. Nat. Neurosci. 20, 1342-1349. https://doi.org/10.1038/nn.4618

So, H.-C., Chau, C.K.-L., Lau, A., Wong, S.-Y., Zhao, K., 2019. Translating GWAS findings into therapies for depression and anxiety disorders: gene-set analyses reveal enrichment of psychiatric drug classes and implications for drug repositioning. Psychol. Med. 49, 26922708. https://doi.org/10.1017/S0033291718003641

Son, H., Baek, J.H., Go, B.S., Jung, D., Sontakke, S.B., Chung, H.J., Lee, D.H., Roh, G.S., Kang, S.S., Cho, G.J., Choi, W.S., Lee, D.K., Kim, H.J., 2018. Glutamine has antidepressive effects through increments of glutamate and glutamine levels and glutamatergic activity in the medial $\begin{array}{llll}\text { prefrontal } \quad \text { cortex. } & \text { Neuropharmacology } & 143-152 .\end{array}$ https://doi.org/10.1016/j.neuropharm.2018.09.040

Song, L., Wang, H., Wang, Y.-J., Wang, J.-L., Zhu, Q., Wu, F., Zhang, W., Jiang, B., 2018. Hippocampal PPAR $\alpha$ is a novel therapeutic target for depression and mediates the antidepressant actions of fluoxetine in mice. Br. J. Pharmacol. 175, 2968-2987. https://doi.org/10.1111/bph.14346

Souery, D., Amsterdam, J., de Montigny, C., Lecrubier, Y., Montgomery, S., Lipp, O., Racagni, G., Zohar, J., Mendlewicz, J., 1999. Treatment resistant depression: methodological overview and operational criteria. Eur. Neuropsychopharmacol. J. Eur. Coll. Neuropsychopharmacol. 9, 83-91.

Souery, D., Serretti, A., Calati, R., Oswald, P., Massat, I., Konstantinidis, A., Linotte, S., Bollen, J., Demyttenaere, K., Kasper, S., Lecrubier, Y., Montgomery, S., Zohar, J., Mendlewicz, J., 2011. Switching antidepressant class does not improve response or remission in treatmentresistant depression. J. Clin. Psychopharmacol. 31, 512-516. https://doi.org/10.1097/JCP.0b013e3182228619

Strawn, J.R., Geracioti, L., Rajdev, N., Clemenza, K., Levine, A., 2018. Pharmacotherapy for generalized anxiety disorder in adult and pediatric patients: an evidence-based treatment review. Expert Opin. Pharmacother. 19, 1057-1070. https://doi.org/10.1080/14656566.2018.1491966

Struzyńska, L., Sulkowski, G., 2004. Relationships between glutamine, glutamate, and GABA in nerve endings under Pb-toxicity conditions. J. Inorg. Biochem. 98, 951-958. https://doi.org/10.1016/j.jinorgbio.2004.02.010

Su, G.Y., Yang, J.Y., Wang, F., Xiong, Z.L., Hou, Y., Zhang, K., Song, C., Ma, J., Song, S.J., Teng, H.F., Wu, C.F., 2014. Xiaochaihutang prevents depressive-like behaviour in rodents by enhancing the serotonergic system: Xiaochaihutang enhancing the 5-HT system. J. Pharm. Pharmacol. n/a-n/a. https://doi.org/10.1111/jphp.12201

Thoeringer, C.K., Erhardt, A., Sillaber, I., Mueller, M.B., Ohl, F., Holsboer, F., Keck, M.E., 2010. Long-term anxiolytic and antidepressant-like behavioural effects of tiagabine, a selective GABA transporter-1 (GAT-1) inhibitor, coincide with a decrease in HPA system activity in C57BL/6 mice. J. Psychopharmacol. Oxf. Engl. 24, 733-743. https://doi.org/10.1177/0269881109103091

Trivedi, M.H., Rush, A.J., Wisniewski, S.R., Nierenberg, A.A., Warden, D., Ritz, L., Norquist, G., Howland, R.H., Lebowitz, B., McGrath, P.J., Shores-Wilson, K., Biggs, M.M., Balasubramani, G.K., Fava, M., STAR*D Study Team, 2006. Evaluation of outcomes with 
citalopram for depression using measurement-based care in STAR*D: implications for clinical practice. Am. J. Psychiatry 163, 28-40. https://doi.org/10.1176/appi.ajp.163.1.28

Tundo, A., de Filippis, R., De Crescenzo, F., 2019. Pramipexole in the treatment of unipolar and bipolar depression. A systematic review and meta-analysis. Acta Psychiatr. Scand. 140, 116125. https://doi.org/10.1111/acps.13055

Vian, J., Pereira, C., Chavarria, V., Köhler, C., Stubbs, B., Quevedo, J., Kim, S.-W., Carvalho, A.F., Berk, M., Fernandes, B.S., 2017. The renin-angiotensin system: a possible new target for depression. BMC Med. 15, 144. https://doi.org/10.1186/s12916-017-0916-3

Wang, J., Um, P., Dickerman, B., Liu, J., 2018. Zinc, Magnesium, Selenium and Depression: A Review of the Evidence, Potential Mechanisms and Implications. Nutrients 10, 584. https://doi.org/10.3390/nu10050584

Williams, L.J., Pasco, J.A., Kessing, L.V., Quirk, S.E., Fernandes, B.S., Berk, M., 2016. Angiotensin Converting Enzyme Inhibitors and Risk of Mood Disorders. Psychother. Psychosom. 85, 250252. https://doi.org/10.1159/000444646

Wirth, M., Schwarz, C., Benson, G., Horn, N., Buchert, R., Lange, C., Köbe, T., Hetzer, S., Maglione, M., Michael, E., Märschenz, S., Mai, K., Kopp, U., Schmitz, D., Grittner, U., Sigrist, S.J., Stekovic, S., Madeo, F., Flöel, A., 2019. Effects of spermidine supplementation on cognition and biomarkers in older adults with subjective cognitive decline (SmartAge)-study protocol for a randomized controlled trial. Alzheimers Res. Ther. 11, 36. https://doi.org/10.1186/s13195-019-0484-1

Wishart, D.S., Feunang, Y.D., Guo, A.C., Lo, E.J., Marcu, A., Grant, J.R., Sajed, T., Johnson, D., Li, C., Sayeeda, Z., Assempour, N., Iynkkaran, I., Liu, Y., Maciejewski, A., Gale, N., Wilson, A., Chin, L., Cummings, R., Le, D., Pon, A., Knox, C., Wilson, M., 2018. DrugBank 5.0: a major update to the DrugBank database for 2018. Nucleic Acids Res. 46, D1074-D1082. https://doi.org/10.1093/nar/gkx1037

Wray, N.R., Ripke, S., Mattheisen, M., Trzaskowski, M., Byrne, E.M., Abdellaoui, A., Adams, M.J., Agerbo, E., Air, T.M., Andlauer, T.M.F., Bacanu, S.-A., Bækvad-Hansen, M., Beekman, A.F.T., Bigdeli, T.B., Binder, E.B., Blackwood, D.R.H., Bryois, J., Buttenschøn, H.N., Bybjerg-Grauholm, J., Cai, N., Castelao, E., Christensen, J.H., Clarke, T.-K., Coleman, J.I.R., Colodro-Conde, L., Couvy-Duchesne, B., Craddock, N., Crawford, G.E., Crowley, C.A., Dashti, H.S., Davies, G., Deary, I.J., Degenhardt, F., Derks, E.M., Direk, N., Dolan, C.V., Dunn, E.C., Eley, T.C., Eriksson, N., Escott-Price, V., Kiadeh, F.H.F., Finucane, H.K., Forstner, A.J., Frank, J., Gaspar, H.A., Gill, M., Giusti-Rodríguez, P., Goes, F.S., Gordon, S.D., Grove, J., Hall, L.S., Hannon, E., Hansen, C.S., Hansen, T.F., Herms, S., Hickie, I.B., Hoffmann, P., Homuth, G., Horn, C., Hottenga, J.-J., Hougaard, D.M., Hu, M., Hyde, C.L., Ising, M., Jansen, R., Jin, F., Jorgenson, E., Knowles, J.A., Kohane, I.S., Kraft, J., Kretzschmar, W.W., Krogh, J., Kutalik, Z., Lane, J.M., Li, Yihan, Li, Yun, Lind, P.A., Liu, X., Lu, L., MacIntyre, D.J., MacKinnon, D.F., Maier, R.M., Maier, W., Marchini, J., Mbarek, H., McGrath, P., McGuffin, P., Medland, S.E., Mehta, D., Middeldorp, C.M., Mihailov, E., Milaneschi, Y., Milani, L., Mill, J., Mondimore, F.M., Montgomery, G.W., Mostafavi, S., Mullins, N., Nauck, M., Ng, B., Nivard, M.G., Nyholt, D.R., O’Reilly, P.F., Oskarsson, H., Owen, M.J., Painter, J.N., Pedersen, C.B., Pedersen, M.G., Peterson, R.E., Pettersson, E., Peyrot, W.J., Pistis, G., Posthuma, D., Purcell, S.M., Quiroz, J.A., Qvist, P., Rice, J.P., Riley, B.P., Rivera, M., Saeed Mirza, S., Saxena, R., Schoevers, R., Schulte, E.C., Shen, L., Shi, J., Shyn, S.I., Sigurdsson, E., Sinnamon, G.B.C., Smit, J.H., Smith, D.J., Stefansson, H., Steinberg, S., Stockmeier, C.A., Streit, F., Strohmaier, J., Tansey, K.E., Teismann, H., Teumer, A., Thompson, W., Thomson, P.A., Thorgeirsson, T.E., Tian, C., Traylor, M., Treutlein, J., Trubetskoy, V., Uitterlinden, A.G., Umbricht, D., Van der Auwera, S., van Hemert, A.M., Viktorin, A., Visscher, P.M., Wang, Y., Webb, B.T., Weinsheimer, S.M., Wellmann, J., Willemsen, G., Witt, S.H., Wu, Y., Xi, H.S., Yang, J., Zhang, F., eQTLGen, 23andMe, Arolt, V., Baune, B.T., Berger, K., Boomsma, D.I., Cichon, S., Dannlowski, U., de 
Geus, E.C.J., DePaulo, J.R., Domenici, E., Domschke, K., Esko, T., Grabe, H.J., Hamilton, S.P., Hayward, C., Heath, A.C., Hinds, D.A., Kendler, K.S., Kloiber, S., Lewis, G., Li, Q.S., Lucae, S., Madden, P.F.A., Magnusson, P.K., Martin, N.G., McIntosh, A.M., Metspalu, A., Mors, O., Mortensen, P.B., Müller-Myhsok, B., Nordentoft, M., Nöthen, M.M., O’Donovan, M.C., Paciga, S.A., Pedersen, N.L., Penninx, B.W.J.H., Perlis, R.H., Porteous, D.J., Potash, J.B., Preisig, M., Rietschel, M., Schaefer, C., Schulze, T.G., Smoller, J.W., Stefansson, K., Tiemeier, H., Uher, R., Völzke, H., Weissman, M.M., Werge, T., Winslow, A.R., Lewis, C.M., Levinson, D.F., Breen, G., Børglum, A.D., Sullivan, P.F., Major Depressive Disorder Working Group of the Psychiatric Genomics Consortium, 2018. Genome-wide association analyses identify 44 risk variants and refine the genetic architecture of major depression. Nat. Genet. 50, 668-681. https://doi.org/10.1038/s41588-018-0090-3

Yang, C., Bosker, F.J., Li, J., Schoevers, R.A., 2018. N-acetylcysteine as add-on to antidepressant medication in therapy refractory major depressive disorder patients with increased inflammatory activity: study protocol of a double-blind randomized placebo-controlled trial. BMC Psychiatry 18. https://doi.org/10.1186/s12888-018-1845-1

Yoon, S.J., Lyoo, I.K., Haws, C., Kim, T.-S., Cohen, B.M., Renshaw, P.F., 2009. Decreased Glutamate/Glutamine Levels May Mediate Cytidine's Efficacy in Treating Bipolar Depression: A Longitudinal Proton Magnetic Resonance Spectroscopy Study. Neuropsychopharmacology 34, 1810-1818. https://doi.org/10.1038/npp.2009.2

Zhang, K., Yang, C., Chang, L., Sakamoto, A., Suzuki, T., Fujita, Y., Qu, Y., Wang, S., Pu, Y., Tan, Y., Wang, X., Ishima, T., Shirayama, Y., Hatano, M., Tanaka, K.F., Hashimoto, K., 2020. Essential role of microglial transforming growth factor- $\beta 1$ in antidepressant actions of (R)ketamine and the novel antidepressant TGF- $\beta 1$. Transl. Psychiatry 10, 32. https://doi.org/10.1038/s41398-020-0733-x

Zhao, K., So, H.-C., 2019. Drug Repositioning for Schizophrenia and Depression/Anxiety Disorders: A Machine Learning Approach Leveraging Expression Data. IEEE J. Biomed. Health Inform. 23, 1304-1315. https://doi.org/10.1109/JBHI.2018.2856535

Zhao, Y.-W., Pan, Y.-Q., Tang, M.-M., Lin, W.-J., 2018. Blocking p38 Signaling Reduces the Activation of Pro-inflammatory Cytokines and the Phosphorylation of p38 in the Habenula and Reverses Depressive-Like Behaviors Induced by Neuroinflammation. Front. Pharmacol. 9, 511. https://doi.org/10.3389/fphar.2018.00511

Zhu, X., Li, W., Li, Y., Xu, W., Yuan, Y., Zheng, V., Zhang, H., O’Donnell, J.M., Xu, Y., Yin, X., 2019. The antidepressant- and anxiolytic-like effects of resveratrol: Involvement of phosphodiesterase-4D inhibition. Neuropharmacology 153, 20-31. https://doi.org/10.1016/j.neuropharm.2019.04.022 